\title{
Long-standing vulvar lipoma in a 65-year-old postmenopausal woman
}

\author{
Ibrahim A. Abdelazim ${ }^{1,2}$ \\ 'Department of Obstetrics and Gynecology, Ahmadi Hospital, Kuwait Oil Company, Kuwait \\ ${ }^{2}$ Department of Obstetrics and Gynecology, Ain Shams University, Cairo, Egypt
}

Corresponding author: Prof. Ibrahim A. Abdelazim, Ahmadi Hospital, Kuwait Oil Company (KOC), Kuwait, P.O. Box: 9758, 61008 Ahmadi, Kuwait, phone: +965-66551300, e-mail: dr.ibrahimanwar@gmail.com

Vulvar lipoma is a rare benign mesenchymal tumor, identified in different age groups [1-4]. The etiology of vulvar lipomas is not clearly identified, while trauma of the vulva is recorded in some cases [5]. The usual presentation of vulvar lipomas is a slowly growing single or multiple painless swelling $[6,7]$.

Vulvar lipomas should be differentiated from other vulvar swellings which have the same clinical presentation, especially liposarcomas [2-4].

Ultrasound is the first cost-effective diagnostic tool which can differentiate vulvar lipomas from other vulvar swellings [2]. Magnetic resonance imaging (MRI) is a useful complementary diagnostic tool in cases of vulvar lipomas to differentiate between vulvar lipomas and liposarcomas $[8,9]$.

This case report presents a rare case of a long-standing vulvar lipoma in a 65-year-old postmenopausal woman.

A 65-year-old Kuwaiti post-menopausal woman, para 6 , presented to the gynecology clinic with a painless, slowly growing swelling of the right vulva over the last 5 years, causing heaviness and discomfort during walking. The local examination revealed a single, soft, painless, freely mobile swelling of the right vulva measuring $13 \times 7.5 \mathrm{~cm}$, with intact overlying skin, without any change in size on straining or coughing.

The swelling had no associated inguinal lymphadenopathy, and no extension in the vagina or towards the pubic bones. The mass was provisionally diagnosed as a vulvar lipoma by radiological evaluation.

After the ultrasound, and the MRI results, the studied woman was admitted to the hospital. After hospitalization, and control of the hypertension, and diabetes, the vulvar mass was excised completely under general anesthesia, and the excised mass was sent for histopathological examination.

The ultrasound evaluation showed non-specific swelling, with homogeneous echogenicity, formed of fat lobules separated by fibrous bands. A departmental decision was taken to confirm the provisional diagnosis using MRI before surgical excision, because vulvar lipomas are rare diseases, and for exclusion of liposarcomas. Magnetic resonance imaging evaluation showed a homogeneous, well-defined, hyper-intense lesion measuring $13 \times 7.5 \mathrm{~cm}$, and fat-suppressed MRI demonstrated a marked decrease in the signal intensity.

After the MRI results, the studied woman was admitted to the hospital, and after the stabilization of her hypertension and diabetes, the vulvar mass was excised completely under general anesthesia (Figure 1).

The histopathology results indicated a circumscribed benign lesion formed of mature adipocytes, confirming the provisional diagnosis of vulvar lipoma (Figure 2).

Vulvar lipoma is a rare benign mesenchymal tumor. Microscopically, the vulvar lipoma appears as lobules of mature fat cells, separated by fibrous connective tissue bands [1-3]. Vulvar lipomas have been identified in different age groups [4], a 27-year-old woman in the Jayi et al. [1] case report, 28- and 35-year-olds in the Odoi et al. [2] case report, and 65-year-old in this case report.

The etiology of vulvar lipomas is not clearly identified, while trauma of the vulva is recorded in some cases [5]. The usual presentation of vulvar lipomas is a slowly growing single or multiple painless swelling. On examination it appears 


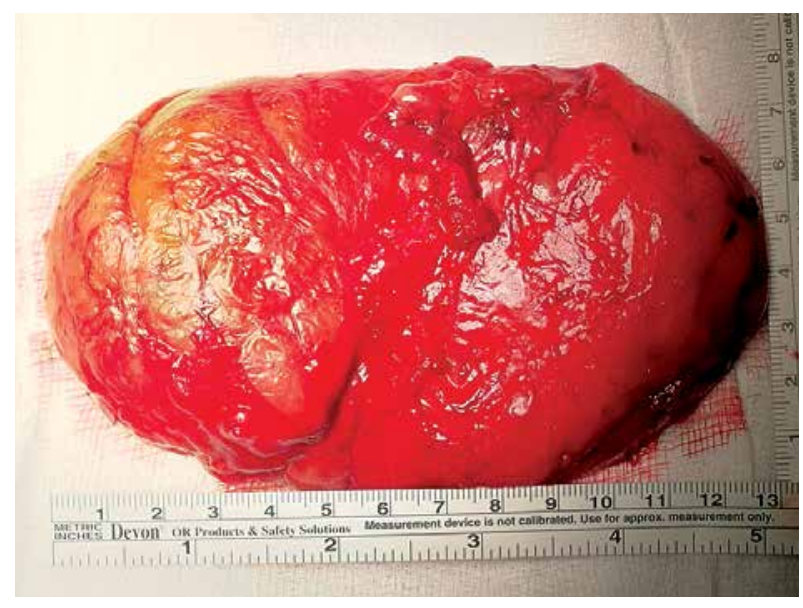

Figure 1. Vulvar swelling after surgical excision measuring $13 \times 7.5 \mathrm{~cm}$

as a well-defined, mobile swelling, of doughy character, with intact overlying skin, not adherent to the surrounding tissue, and without associated lymphadenopathy $[2,6,7]$.

Vulvar lipomas should be differentiated from other vulvar swellings which have the same clinical presentation, especially liposarcomas, Bartholin's gland swellings, Nuck's canal cysts, and inguinal hernias [2-4].

Ultrasound is the first cost-effective diagnostic tool which can differentiate vulvar lipomas from other vulvar swellings [2]. Vulvar lipoma appears by ultrasound as a non-specific swelling, with homogeneous echogenicity, formed of fat lobules separated by fibrous bands $[2,7,8]$.

Magnetic resonance imaging is a useful complementary diagnostic tools in cases of vulvar lipomas to differentiate between vulvar lipomas and liposarcomas, through evaluation of the tumor extensions and/or connections to the surrounding structures $[8,9]$.

Ohguri et al. [9] found that the septa showed moderate or marked enhancement in well-differentiated liposarcomas, whereas the septa in well-differentiated liposarcomas enhanced more strongly than did those in benign lipomas, and lipomas with a thin septum or fibrous bands are not enhanced on contrast-enhanced MRI [10].

Surgical excision is the best treatment option for vulvar lipomas, because it allows exclusion of any malignant involvement or components after histopathological examination of the excised lesion $[2,3]$.

The histopathological appearance of the lipomas usually shows a well-circumscribed benign lesion formed of mature adipocytes, separated by connective tissue bands [4].

Recurrence of vulvar lipomas is possible, and the surgeon should expect liposarcomas or malignant components if short-term recurrence occurs after compete excision of the lipomas [11].

Poncelet et al. [11] recorded short-term recurrence in a 31-year-old woman initially treated for a vulvar lipoma. The histological results of the excised mass showed infiltrating adipocytes and cytogenetic findings of well-differentiated liposarcoma.

Vulvar lipoma is an extremely rare disease, which has the same clinical presentation as liposarcoma. The diagnosis

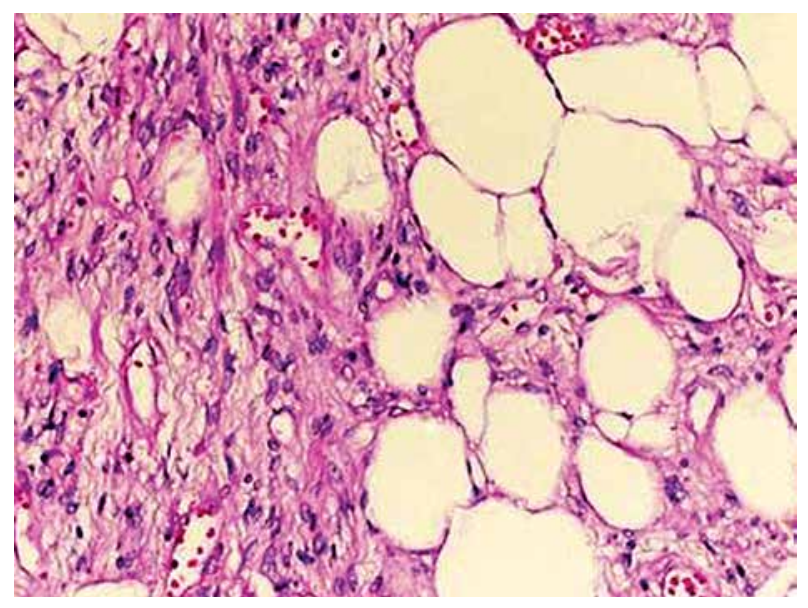

Figure 2. Microscopic appearance of the vulvar swelling as lobules of mature adipocytes (vulvar lipoma)

of vulvar lipoma should be confirmed after surgical excision and histopathological examination of the excised lesion.

\section{Acknowledgments}

The author is grateful to the studied woman, who agreed to participate in the study.

\section{Conflict of interest}

The author declares no conflict of interest.

\section{References}

1. Jayi S, Laadioui M, El Fatemi H, et al. Vulvar lipoma: a case report. J Med Case Rep 2014; 8: 203.

2. Odoi AT, Owusu-Bempah A, Dassah ET, Darkey DE, Quayson SE. Vulvar lipoma: is it so rare? Ghana Med J 2011; 45: 125-7.

3. Jung HL, Seung MC. Large vulvar lipoma in an adolescent: a case report. J Korean Med Sci 2008; 23: 744-6.

4. Jourjon R, Dohan A, Brouland JP, Guerrache Y, Fazel A, Soyer P. Angiolipoma of the labia majora: MR imaging findings with histopathological correlation. Clin Imaging 2013; 37: 965-8.

5. Aust MC, Spies M, Kall S, et al. Lipomas after blunt soft tissue trauma: are they real? Analysis of 31 cases. Br J Dermatol 2007; 157: 92-9.

6. Salam GA. Lipoma excision. Am Fam Physician 2002; 65: 901-4.

7. Oh JT, Choi SH, Ahn SG, Kim MJ, Yang WI, Han SJ. Vulvar lipomas in children: an analysis of 7 cases. J Pediatr Surg 2009; 44: 1920-3.

8. Ogasawara Y, Ichimiya M, Nomura S, Muto M. Perineallipoma in a neonate. J Dermatol 2001; 28: 165-7.

9. Ohguri T, Aoki T, Hisaoka M, et al. Differential diagnosis of benign peripheral lipoma from well-differentiated liposarcoma on MR imaging: is comparison of margins and internal characteristics useful? AJR Am J Roentgenol 2003; 180: 1689-94.

10. Murphey MD, Carroll JF, Flemming DJ, Pope TL, Gannon FH, Kransdorf MJ. From the archives of the AFIP: benign musculoskeletal lipomatous lesions. Radiographics 2004; 24: 1433-66.

11. Poncelet C, Boccara J, Walker-Combrouze F, Féraud O, Madelenat $\mathrm{P}$. Atypical lipomatous tumour of the vulva. About one case [French]. Gynécol Obstét Fertil 2004; 32: 46-8. 